\title{
The reversed Birth Satisfaction Scale: Translation, adaptation and validation for a Greek sample
}

\author{
Victoria G. Vivilaki ${ }^{1}$, Eleni Zemperligkou ${ }^{1}$, Eirini Iliopoulou ${ }^{1}$, Eirini Anastasopoulou ${ }^{1}$, \\ Paraskevi Giaxi $^{1}$, Katerina Lykeridou ${ }^{1}$
}

\begin{abstract}
INTRODUCTION The Birth Satisfaction Scale (BSS) is an important screening instrument that is used with mothers during the postpartum period for the identification of postnatal birth satisfaction. The purpose of this study was to validate and adapt the Greek version of the BSS to test its sensitivity, specificity and predictive values.

METHODS Childbearing women $(n=310)$ were recruited from the perinatal care registers of the Maternity Departments of 3 Hospitals of Athens municipality (public Maternity Departments) in 2014. Inclusion criteria included fluency in spoken and written Greek language, within 1-4 postpartum days, and delivery of a healthy infant. Exploratory Factor Analysis (EFA) on the 30-items on the BSS revealed 7 orthogonal factors (KMO measure of sampling adequacy $=0.856$ and Bartlett's test of sphericity $=2999.806, d f=435, p<0.0005)$. A Receiver Operating Characteristic (ROC) analysis was conducted to evaluate global functioning of the scale. Within this context the scoring of the BSS was reversed from the original, to indicate that a lower score was a worse outcome.

RESULTS The Greek BSS showed high overall internal consistency (Cronbach's alpha value: 0.876, $\mathrm{p}<0.0001)$. The internal consistency characteristics of the Greek BSS showed good reliability: Cronbach's alpha was 0.876 for the total scale (Items 1-30), Standardized alpha 0.859 and Guttman split-half 0.864, Spearman-Brown 0.866. Our findings confirm the multidimensionality of BSS, demonstrating a seven-factor structure that contained subscales, reflecting the postnatal birth satisfaction. Exploratory Factor Analysis (EFA) demonstrated that the 7-factor model offered a very good fit to our data. The area under the minor satisfaction ROC curve is 0.796 ( $S D=0.025$, Asymp. Sig. $=0.0005 ; \mathrm{Cl}=0.748-0.845$ ), sensitivity $=73.8 \%$, and specificity $=70 \%$.

concLusions Our data confirm the validity of the Greek version of the BSS at identifying postnatal birth satisfaction. Hence, the Greek BSS could be used as a useful instrument in both clinical practice and research.
\end{abstract}

\author{
AFFILIATION \\ 1 Midwifery Department \\ of Athens, Technological \\ Educational Institute of Athens, \\ Athens, Greece
}

\section{CORRESPONDENCE TO \\ Midwifery Department of Athens, Technological Educational Institute of Athens, Passionos 44-46, 11631 Athens, Greece. E-mail: v.vivilaki@gmail.com}

\section{KEYWORDS}

screening, validation, quality, postpartum, services, childbirth satisfaction

$\checkmark$

Received: 17 April 2017 Revised: 21 August 2017 Accepted: 24 August 2017

List of abbreviations used

BSS: Birth Satisfaction Scale

ROC: Receiver Operating Characteristic

AUC: Area Under Curve

KMO: Kaiser-Meyer-Olkin

\section{INTRODUGTION}

Birth satisfaction is important in terms of both 'cost' and 'quality'. In this respect, healthcare cannot be high quality unless the woman is satisfied with the care she has received ${ }^{2}$, within a prescribed system and budget. Since every woman creates childbirth expectations differently and appreciation varies ${ }^{3,4}$, it is important that women's birth experiences are evaluated. In terms of quantitative research, a woman's satisfaction with intrapartum care can only be considered high quality when gratification is high in relation to the care she has received ${ }^{2}$. A plethora of research has highlighted the wide spectrum of satisfaction with maternity care, however only a small number of validated scales has examined specifically satisfaction with intrapartum care ${ }^{5,6}$.

Meaningful measurement of birth satisfaction can only be achieved using a rigorous, valid and reliable psychometric instrument, and 


\section{Research paper}

for this purpose Hollins Martin and Fleming ${ }^{7}$ developed a 30-item psychometric scale (Birth Satisfaction Scale, BSS) to assess women's levels of birth satisfaction. The BSS was developed to facilitate researchers, maternity care staff and consumers to construct a meaningful picture of what in fact constitutes a woman's like or dislike of her birth experience ${ }^{7}$. To date, the scale has been validated in Scotland $(\mathrm{UK})^{8}, \mathrm{USA}^{9}$, and Greece (Athens) $)^{10}$. In the Greek validation study $^{10}$, the sample of participants was considered to be small $(n=162)$ and conducted via Internet, and therefore the purpose of the present study was to further validate (evaluate also the sensitivity and specificity) of the BSS for use within a population of Greek women between 1-4 postpartum days.

The aim of the present study was to determine the factor structure, validity and reliability of the Greek version of the BSS, and to consider creating a short-form version of the tool. Thus, the objectives of this study were to:

1. Test a Greek version of the BSS and assess its reliability and validity at measuring postnatal women's birth satisfaction in a sample of new mothers.

2. Examine the factor structure of the Greek BSS.

3. Evaluate the sensitivity, specificity and predictive values of the Greek BSS over a range of cut-off scores.

4. Potentially adapt the BSS score so that it reflects a simpler way of scoring.

\section{METHOD}

\section{Translation and pilot study}

The 30-item BSS was translated by 2 independent bilingual translators. One other native English speaker, who did not have knowledge of the original instrument, then back- translated the reconciliated Greek version. The backward translation was sent to a group of English experts (health professionals with specialization in perinatal psychology) for comments. The translated questionnaire was culturally adapted through a cognitive debriefing process that was used to identify any language problems and to assess the degree of respondents' understanding of the item content that was meant to be elicited ${ }^{11}$. In a pilot study, the new Greek version of the BSS was tested with 8 mothers. As part of the cultural-adaptation process, in-depth interviews were conducted to test respondents' understanding of scale items. Participants gave their views about the clarity of each item, the relevance of the content to their situation, the comprehensiveness of the instructions, and their ability to complete the Greek version BSS on their own.

\section{Data collection}

After receiving ethical approval (from the Ethical Boards of the two Hospitals), validation activities were initiated March-November 2014. Following correspondence by email and subsequent written informed consent, the mothers completed the BSS in the presence of the midwives in their homes or the postnatal ward. A cover letter explained the purpose of the study, provided the researchers' affiliation and contact information, and guaranteed confidentiality and anonymity. In addition to standard demographic questions, mothers completed the BSS questionnaire in the presence of a midwife during their stay at the postnatal ward. The order of completion of the two questionnaires was counterbalanced. Mothers were encouraged to discuss any concerns they might have and were told that the chief midwife would be informed of their responses to the screening.

\section{Participants}

The study was conducted in the two largest maternity public hospitals (Alexandra and Elena) in Greece that serve the population of Athens, as well as women from the rural areas of Greece. Childbearing women ( $n=310 ; 92.3 \%)$ were recruited from the perinatal care registers of the Maternity Departments of 2 Hospitals of Athens municipality (public Maternity Departments). To enhance the representativeness of the study sample, one researcher (VV), created a calendar to ensure balance across shifts and days of week. More specifically, the women were recruited at a steady rate, one day each week (i.e. first on Monday, the following week on Tuesday, the week following on Wednesday, etc.), to avoid bias associated with day of week delivered. Each recruitment day was split into three shifts (8 a.m., 4 p.m., 12 a.m.), with the first four women who had given birth after 8 a.m. approached one week, and the first four women who gave birth after 4 p.m. approached the following week, etc., to reduce possible bias regarding mode of delivery related to the time of delivery and to avoid over selection of caesarean-section women. Women were eligible for participation if they were: (1) aged between 18 and 45 years, (2) between 1-4 postpartum days after the delivery of a healthy infant, (3) fluent in spoken and written Greek, and (4) able to provide informed written consent. The women were screened for eligibility criteria by the midwife-researchers that visited them during their stay in the postnatal ward. A total of 310 women were recruited from the perinatal-care registers of the Maternity Departments of 2 Hospitals of Athens municipality (public Maternity Departments).

\section{INSTRUMENTS}

The BSS is a 30-item self-report scale that consists of statements that represent birth satisfaction ${ }^{8,12}$. Each item is scored on a 5-point Likert scale ranging from $0-4$, with response options that range from 0 (totally satisfied) to 4 (not at all satisfied), and a total score is calculated (0-120). Items that measure negative statements are reverse-scored. With a lower score indicating more positive maternal birth experience. The 30-item scale includes the following core subscales:

1) Quality of care provision: (a) Home assessment ${ }^{12,26}$; (b) Birth environment ${ }^{14,28}$; (c) Sufficient support ${ }^{10,24}$; (d) Relationships with health care professionals ${ }^{13,27}$.

2) Women's personal attributes: (a) Ability to cope during labour ${ }^{1,15}$; (b)Feeling in control2,16; (c)Preparation for childbirth ${ }^{3,17}$; (d)Relationship with baby ${ }^{11,25}$.

3) Stress experienced during labour: (a) Distress experienced during labour ${ }^{4,18}$; (b)Obstetric injuries ${ }^{5,19}$; (c)Perception of having received sufficient medical care 7,21; (d)Receipt of an obstetric intervention ${ }^{8,22}$; (e)Pain experienced ${ }^{29,30}$; (f)Long labour ${ }^{9}, 23$; (g)Health of baby ${ }^{6,20}$.

Within the context of the Greek setting, it was noted that this 'negative scoring', i.e. that a lower score was actually a better outcome, was not easily understood within Greek clinical practice and hence within the current approach the BSS scoring was reversed so that a lower score would mean a lower birth-satisfaction, while a higher score would mean better satisfaction.

\section{Data analysis}

Statistical analysis was performed using IBM SPSS Statistics Version ${ }^{19}$. Descriptive characteristics (including means, standard deviations, frequencies and percentages) were calculated for the socio-demographic variables. Assumptions of normality, homogeneity and independent cases of the sample were checked. Two independent 


\section{Research paper}

samples t-tests were carried out to compare BSS scores in the groups of satisfied and not-satisfied women, according to the gold-standard question (Did you have a satisfying birth experience?). Women were divided into 2 groups: satisfied (YES) and not-satisfied (NO).

\section{Reliability}

Reliability coefficients measured by Cronbach's alpha were calculated to assess reproducibility and consistency of the instrument; the internal consistency of the Greek BSS was also tested using Guttman split-half coefficients.

\section{Factor structure}

The underlying dimensions of the scale were checked with an Explanatory Factor Analysis (EFA) using a varimax rotation and Principal Components Method, as is the usual descriptive method for analysing grouped data ${ }^{13}$. Principal Component Analysis with varimax rotation was conducted to determine the dimensional structure using: (a) eigenvalue $>114$, (b) variables load $>0.50$ on only one factor and on other factors less than 0.40 , (c) interpretation of factor structure is meaningful, (d) Scree plot is accurate with means of Communalities above 0.6015. Computations were based on a covariance matrix, as all variables were receiving values from the same measurement scale ${ }^{16}$; during factor analysis, a Bartlett's test of sphericity $(p<0.05)$ and a Kaiser-Meyer-Olkin (KMO) measured sampling adequacy of 0.856 , were also implemented. A factor was considered important if its eigenvalue exceeded 114, with factor analysis identifying 7 independent subscales. Subsequent Cronbach's alpha was carried out on each subscale, to highlight how items grouped together.

\section{Face and content validity}

The research midwife investigated the meaning and acceptability of BSS items during the administration of the scale.

\section{Criterion validity}

Validity of the Greek-BSS (as a screening tool) was investigated by considering answers to the question ('I was not satisfied at all during my labour'), as a validated measure for classifying satisfied and notsatisfied mothers. As a result, the status satisfied was measured as $\mathrm{O}$ (non-disease) and the status not-satisfied (disease) was measured as 1. The diagnostic performance of BSS, or the accuracy of BSS to discriminate 'diseased cases' (not- satisfied) from 'normal cases' (satisfied) was evaluated using Receiver Operating Characteristic (ROC) curve analysis. It is important to note that within this context the BSS scale was reversed from the original BSS scale to reflect this approach.

\section{Sensitivity and specificity}

The sensitivity, specificity, and positive/negative predictive values were calculated at several cut-off scores. A Receiver Operating Characteristic (ROC) analysis displayed pairs of sensitivity and specificity values, as the threshold changed from low to high scores (by plotting the truepositive rate [sensitivity] on the vertical axis and the false-positive rate [one minus specificity] on the horizontal axis). The area under the ROC curve (AUC) is a quantitative indicator of the information content of a test and it may be interpreted as an estimate of the probability that a satisfied mother chosen at random will, at each threshold, have a higher test score than a not-satisfied mother.

\section{RESULTS}

Sample characteristics

The response rate (90\%) was high, with sample demographic and

\section{Table 1. Characteristics of sample}

\begin{tabular}{|c|c|c|}
\hline & & According to BSS \\
\hline & Frequency $(n)$ & $4(8.1 \%)$ \\
\hline \multicolumn{3}{|l|}{ Age } \\
\hline$<25$ & 26 & 8,5 \\
\hline $26-35$ & 213 & 69,6 \\
\hline $36-45$ & 67 & 21,9 \\
\hline \multicolumn{3}{|l|}{ Nationality } \\
\hline Greek & 276 & 89,9 \\
\hline Other & 31 & 10,1 \\
\hline \multicolumn{3}{|c|}{ Educational Status } \\
\hline High School & 22 & 7,1 \\
\hline Lyceum & 117 & 37,7 \\
\hline University & 133 & 42,9 \\
\hline $\mathrm{MSc} / \mathrm{PhD}$ & 38 & 12,3 \\
\hline \multicolumn{3}{|l|}{ Work Status } \\
\hline Housewife & 47 & 15,2 \\
\hline Unemployed & 61 & 19,7 \\
\hline Student & 4 & 1,3 \\
\hline $\begin{array}{l}\text { Private } \\
\text { Servant }\end{array}$ & 46 & 14,8 \\
\hline $\begin{array}{l}\text { Private } \\
\text { Employee }\end{array}$ & 108 & 34,8 \\
\hline Independent & 32 & 10,3 \\
\hline Other & 12 & 3,9 \\
\hline
\end{tabular}

Family income per month (euros)

500-1000

133

$1000-2000$

133

$2000-3000$

94

44

$>3000$

35

31,1

11,6

40

13,2

Psychological Problem

No

253

82,1

Yes

55

17,9

Family Status

$\begin{array}{lcc}\text { Married } & 105 & 33,9 \\ \text { Single } & 195 & 62,9 \\ \text { Divorced } & 1 & 0,3 \\ \text { Partner } & 9 & 2,9\end{array}$

\section{Other Children}

$\begin{array}{lll}\text { Primigravida } & 159 & 51,3\end{array}$

Multigravida

151

48,7

\section{Any Miscarriage}

No

251

81

Yes

59

19

\section{Any Abortion}

No

265

85,8

Yes

44

14,2 


\section{Research paper}

\begin{tabular}{|c|c|c|c|}
\hline \multicolumn{3}{|l|}{ Pregnancy } & \multirow{2}{*}{$\begin{array}{l}\text { obstetric characteristics shown in Table } 1 \text {. Of the women, }(n=159 \text {; } \\
51.3 \%) \text { were primaparae and }(n=151 ; 48.7 \%) \text { were multiparae. } \\
\text { Mean BSS score was } 38.15 \text { (SD 14.319, Skewness 205.031, Std }\end{array}$} \\
\hline Random & 126 & 40,6 & \\
\hline Scheduled & 184 & 59,4 & Error of Skewness 0.033 , Kurtosis 0.138 , Std Error of Kurtosis \\
\hline \multicolumn{3}{|c|}{ Duration of Gestation } & \multirow{7}{*}{ 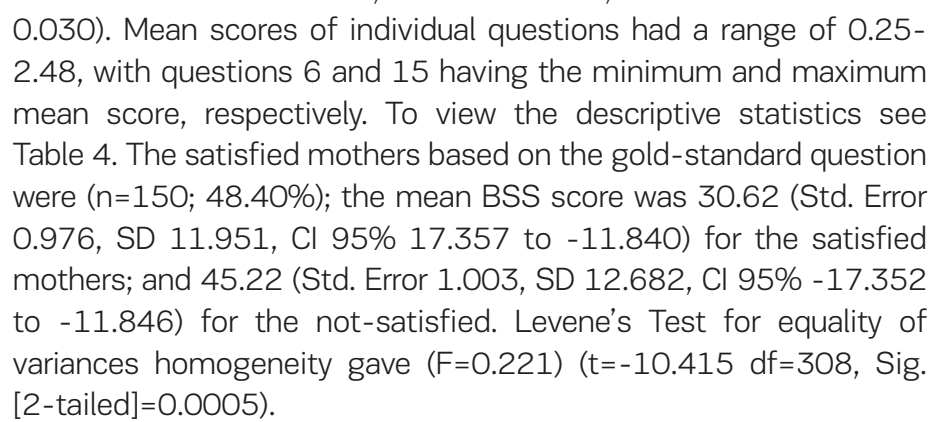 } \\
\hline$<37$ weeks & 93 & 30 & \\
\hline 37-42 weeks & 206 & 66,5 & \\
\hline$>42$ weeks & 11 & 3,5 & \\
\hline \multicolumn{3}{|l|}{ Delivery } & \\
\hline $\begin{array}{l}\text { Normal } \\
\text { Childbirth }\end{array}$ & 132 & 42,6 & \\
\hline $\begin{array}{l}\text { Caesarean } \\
\text { Section }\end{array}$ & 175 & 56,5 & \\
\hline
\end{tabular}

Forceps 3

$\begin{array}{lcc}\text { Epidural } & & \\ \text { No } & 57 & 32,9 \\ \text { Yes } & 116 & 67,1\end{array}$

\begin{tabular}{lll} 
Episiotomy & & \\
No & 144 & 83,2 \\
\hline
\end{tabular}

$\begin{array}{lll}\text { Yes } & 29 & 16,8\end{array}$

$\begin{array}{lll}\text { Place of Labour } & \\ \text { Hospital } & 259 & 97,7\end{array}$

$\begin{array}{lll}\text { House } & 6 & 2,3\end{array}$

\begin{tabular}{lcc|}
\hline Acting Childbirth & & \\
Doctor & 257 & 97 \\
Midwife & 8 & 3
\end{tabular}

$\begin{array}{lcc}\text { Enema } & & \\ \text { No } & 38 & 14,3 \\ \text { Yes } & 227 & 85,7\end{array}$

Urination during Labour
Catheters

$\begin{array}{lcc}\text { Catheters } & 173 & 65,3 \\ \text { Bedpan } & 74 & 27,9 \\ \text { WC } & 18 & 6,8\end{array}$

Liquid consumption during Labour

$\begin{array}{lcc}\text { No } & 243 & 91,7 \\ \text { Yes } & 22 & 8,3\end{array}$

Mobility and Change of Position

$\begin{array}{lll}\text { No } & 150 & 56,6 \\ \text { Yes } & 115 & 43,4\end{array}$

Newborn Nutrition

\begin{tabular}{lcc} 
Breastfeeding & 107 & 65,2 \\
$\begin{array}{l}\text { More } \\
\text { frequently } \\
\text { breastfeeding }\end{array}$ & 41 & 25 \\
$\begin{array}{l}\text { More } \\
\text { frequently } \\
\text { formula milk } \\
\text { Formula milk }\end{array}$ & 8 & 2,6 \\
Apgar test = 10 & 8 & \\
No & & 2,6 \\
Yes & 9 & 5,4 \\
\hline
\end{tabular}

\section{Psychometric characteristics of Greek BSS}

Reliability

The Greek-BSS showed a very high overall internal consistency (Cronbach's alpha value: $0.876, p<0.0001$ ). The internal consistency characteristics showed good reliability (Cronbach's alpha was 0.876 for the total scale [Items 1-30], Standardized alpha 0.859 and Guttman split-half 0.864, Spearman-Brown 0.866).

\section{Factor Structure}

Exploratory factor analysis

The exploratory factor analysis on the 30-item Greek-BSS revealed 7 orthogonal factors (KMO measure of sampling adequacy $=0.856$ and Bartlett's test of sphericity=2999.806, df=435, $p<0.0005$ ). Communalities for Greek BSS questions are presented in Table 2. The Scree plot (Figure 1) and Component plot in Rotated Space (Figure 2) indicate that there are 7 factors in the model, with these factors explaining $56.250 \%$ of the data (Table 2). The first factor (F1) includes the following items: 27 (Relationships with health-care professionals), 24 (Sufficient support), 14 and 28 (Birth environment), 7 and 21 (Perception of having received sufficient medical care) and 2 (Feeling in control). These are sufficient staff attitudes for pregnant women; therefore, we named this subscale 'Quality of care'. The second factor (F2) is composed of items 30 and 29 (Pain experienced), 4 and 18 (Distress experienced during labour), 26 (Home assessment), 23 and 9 (Long labour). Therefore, F2 represents 'Pain and Stress management'. The third factor (F3) includes the following items: 17 and 3 (Preparation for childbirth), 16 (Feeling in control), 15 (Ability to cope during labour), 12 (Home assessment), 10 (Sufficient support). Therefore, F3 represents 'Feelings and Support during labour'. The fourth factor (F4) is composed of items 22 and 8 (Receipt of an obstetric intervention) and was named 'Medicalization'. The fifth factor (F5) consists of items 20 (Health of baby) and 19 (Obstetric injuries); therefore, we named this subscale 'Birth Experience'. The sixth factor (F6) includes the following items: 6 (Health of baby) and 5 (Obstetric injuries). Therefore, the F6 represents 'Healthy Mother and Baby'. Finally, the seventh factor (F7) is composed of items 25 and 11 (Relationship with baby) and was named 'Skin-to-Skin'.

\section{Validity}

Face and content validity

The Greek-BSS was well accepted by the mothers. It was easily and very quickly completed (approximately 10 minutes). The questions appeared to be relevant, reasonable, unambiguous and clear. 


\section{Research paper}

Table 2. Exploratory factors and Explained Variance after rotation for the Greek BSS

\begin{tabular}{|c|c|c|c|c|c|c|c|}
\hline \multirow[t]{2}{*}{ Factors } & & \multicolumn{6}{|c|}{ Rotation Sums of Squared Loadings } \\
\hline & & $\begin{array}{l}\text { Rescaled } \\
\text { Loadings }\end{array}$ & $\begin{array}{l}\text { Eigen } \\
\text { values }\end{array}$ & $\begin{array}{l}\% \text { of } \\
\text { Variance }\end{array}$ & $\begin{array}{l}\text { Cumulative } \\
\text { Variance }\end{array}$ & $\begin{array}{l}\text { Cronbach's } \\
\text { alpha }\end{array}$ & $\begin{array}{l}\text { Standardised } \\
\text { alpha }\end{array}$ \\
\hline \multirow{7}{*}{$\frac{\text { Factor I }}{\text { (Quality of care) }}$} & Question 27 & 0.725 & 7.008 & 23.361 & 23.361 & 0.801 & 0.801 \\
\hline & Question 24 & 0.708 & & & & & \\
\hline & Question 14 & 0.657 & & & & & \\
\hline & Question 7 & 0.622 & & & & & \\
\hline & Question 28 & 0.620 & & & & & \\
\hline & Question 21 & 0.615 & & & & & \\
\hline & Question 2 & 0.568 & & & & & \\
\hline \multirow{7}{*}{$\begin{array}{l}\frac{\text { Factor II }}{\text { (Pain and Stress }} \\
\text { management) }\end{array}$} & Question 30 & 0.775 & 2.872 & 9.574 & 32.935 & 0.802 & 0.802 \\
\hline & Question 4 & 0.705 & & & & & \\
\hline & Question 26 & 0.606 & & & & & \\
\hline & Question 29 & 0.596 & & & & & \\
\hline & Question 23 & 0.565 & & & & & \\
\hline & Question 9 & 0.543 & & & & & \\
\hline & Question 18 & 0.430 & & & & & \\
\hline \multirow{6}{*}{$\begin{array}{l}\text { Factor III } \\
\text { (Feelings and } \\
\text { Support during labour) }\end{array}$} & Question 17 & 0.735 & 1.984 & 6.614 & 39.549 & 0.659 & 0.665 \\
\hline & Question 3 & 0.589 & & & & & \\
\hline & Question 16 & 0.540 & & & & & \\
\hline & Question 15 & 0.490 & & & & & \\
\hline & Question 12 & 0.453 & & & & & \\
\hline & Question 10 & 0.452 & & & & & \\
\hline \multirow{2}{*}{$\frac{\text { Factor IV }}{\text { (Medicalization) }}$} & Question 22 & 0.882 & 1.434 & 4.781 & 44.330 & 0.846 & 0.846 \\
\hline & Question 8 & 0.881 & & & & & \\
\hline \multirow{2}{*}{$\frac{\text { Factor V }}{\text { (Birth Experience) }}$} & Question 20 & 0.750 & 1.305 & 4.351 & 48.681 & 0.706 & 0.711 \\
\hline & Question 19 & 0.552 & & & & & \\
\hline \multirow{2}{*}{$\begin{array}{l}\text { Factor VI } \\
\text { (Healthy Mother and } \\
\text { Baby) }\end{array}$} & Question 6 & 0.745 & 1.162 & 3.873 & 52.554 & 0.537 & 0.564 \\
\hline & Question 5 & 0.507 & & & & & \\
\hline \multirow{2}{*}{$\frac{\text { Factor VII }}{\text { (Skin-to-Skin) }}$} & Question 25 & 0.754 & 1.109 & 3.695 & 56.250 & 0.530 & 0.531 \\
\hline & Question 11 & 0.529 & & & & & \\
\hline
\end{tabular}




\section{Research paper}

Table 3. Sensitivity, specificity of different cut-off scores of the Greek BSS for identifying positive or negative maternal birth experience

\begin{tabular}{|ccc|}
$\begin{array}{c}\text { Threshold } \\
\text { scores }\end{array}$ & $\begin{array}{c}\text { Sensitivity } \\
\text { (\%) }\end{array}$ & $\begin{array}{c}\text { Specificity } \\
\text { (\%) }\end{array}$ \\
\hline 31 & 85 & 52.7 \\
\hline 34 & 80.6 & 58.7 \\
\hline 35 & 80 & 62.7 \\
\hline 36 & 78.8 & 66.7 \\
\hline 37 & 73.8 & 70 \\
\hline 38 & 70.6 & 70.7 \\
\hline 39 & 66.9 & 73.3 \\
\hline 40 & 62.5 & 76.7 \\
\hline 41 & 59.4 & 80 \\
\hline 43 & 55 & 84.7 \\
\hline
\end{tabular}

Therefore, face validity was considered to be good. The content of Greek-BSS, with the reversed scoring, includes in a balanced way the full scope of the characteristics of postnatal birth satisfaction that it is intended to measure.

\section{Criterion validity}

The overall accuracy of the Greek-BSS as a screening instrument can be described as the area under its ROC curve. The curve was plotted considering, for the BSS scores, a range between 1 and 81 (the maximum score reached by one satisfied subject in our sample). The area under the minor satisfaction ROC curve is 0.796 (SD=0.025, Asymp. Sig. $=0.0005 ; \mathrm{Cl}=0.748-0.845)$. Analysing the scale sensitivity in the detection of satisfied women at the 37 cut-off score, the sensitivity was $73,8 \%$ and specificity $70 \%$ (Table 3 \& Figure 3).

Figure 4 shows the accuracy of the Greek-BSS in screening the mothers that participated in this study for postnatal birth satisfaction. The plot of the curves offers an excellent visual comparison of model performance, and the area-under-the-curve table gives evidence to back up conclusions.

Table 4. Descriptive Statistics of Questions of BSS

\begin{tabular}{|c|c|c|c|c|}
\hline Question & Mean Range & St.Deviation & Skewness/Std Error of Skewness & Kurtosis/Std Error of Kurtosis \\
\hline 1 & 0,67 & 0,720 & 0,518/0,997 & $0,138 / 1,351$ \\
\hline 2 & 0,87 & 0,951 & $0,905 / 1,062$ & $0,138 / 0,679$ \\
\hline 3 & 1,44 & 1,074 & $1,154 / 0,372$ & $0,138 /-0,587$ \\
\hline 4 & 1,92 & 1,132 & $1,282 /-0,022$ & $0,138 /-0,747$ \\
\hline 5 & 0,65 & 0,743 & $0,551 / 1,139$ & $0,138 / 1,561$ \\
\hline 6 & 0,25 & 0,499 & $0,249 / 1,972$ & $0,138 / 4,072$ \\
\hline 7 & 0,43 & 0,664 & $0,440 / 2,082$ & $0,138 / 6,862$ \\
\hline 8 & 2,43 & 1,545 & $2,388 /-0,547$ & $0,138 /-1,273$ \\
\hline 9 & 1,14 & 1,135 & $1,287 / 0,856$ & $0,138 /-0,054$ \\
\hline 10 & 0,87 & 1,079 & $1,164 / 1,433$ & $0,138 / 1,609$ \\
\hline 11 & 1,02 & 1,107 & $1,226 / 0,961$ & 0,138/0,035 \\
\hline 12 & 2,44 & 1,162 & $1,351 /-0,366$ & $0,139 /-0,849$ \\
\hline 13 & 1,32 & 1,171 & $1,371 / 0,591$ & $0,138 /-0,664$ \\
\hline 14 & 0,91 & 0,854 & $0,730 / 0,864$ & $0,138 / 0,619$ \\
\hline 15 & 2,48 & 1,232 & $1,519 /-0,407$ & $0,138 /-0,946$ \\
\hline 16 & 1,42 & 1,165 & $1,358 / 0,658$ & $0,138 /-0,447$ \\
\hline 17 & 1,28 & 1,180 & $1,393 / 0,831$ & $0,138 /-0,204$ \\
\hline 18 & 1,69 & 1,237 & $1,530 / 0,303$ & $0,138 /-0,882$ \\
\hline 19 & 0,94 & 0,941 & $0,886 / 1,177$ & $0,138 / 1,587$ \\
\hline 20 & 0,67 & 0,814 & $0,663 / 1,404$ & $0,138 / 2,565$ \\
\hline 21 & 0,59 & 0,752 & $0,566 / 1,616$ & $0,138 / 3,561$ \\
\hline 22 & 2,36 & 1,526 & $2,329 /-0,324$ & $0,138 /-1,453$ \\
\hline 23 & 1,59 & 1,273 & $1,621 / 0,457$ & $0,138 /-0,932$ \\
\hline 24 & 0,60 & 0,669 & $0,448 / 1,064$ & $0,138 / 1,903$ \\
\hline 25 & 1,28 & 1,189 & $1,413 / 0,746$ & $0,138 /-0,390$ \\
\hline 26 & 1,78 & 1,145 & $1,311 / 0,243$ & 0,138/-0,717 \\
\hline 27 & 0,71 & 0,766 & $0,587 / 1,148$ & $0,138 / 1,883$ \\
\hline 28 & 0,70 & 0,691 & $0,477 / 0,532$ & $0,139 /-0,565$ \\
\hline 29 & 1,87 & 1,309 & $1,714 / 0,203$ & $0,138 /-1,127$ \\
\hline 30 & 1,84 & 1,164 & $1,355 / 0,250$ & $0,138 /-0,774$ \\
\hline
\end{tabular}




\section{Research paper}

\section{Figure 1. Scree plot}

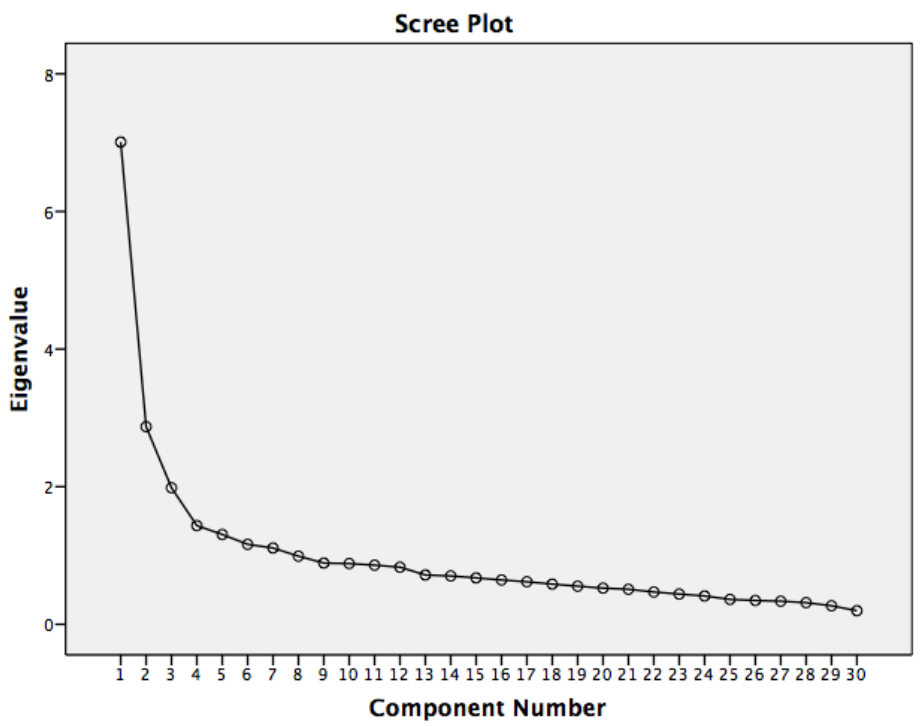

Figure 2. Component plot in Rotated Space

Component Plot in Rotated Space

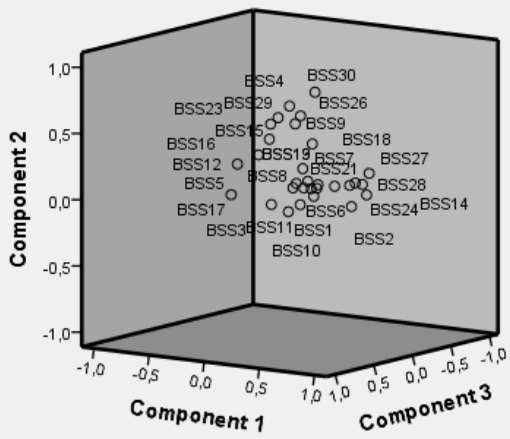

\section{Construct validity}

Convergent validity: for the Greek-BSS (Mean=38.15, SD=0.813), normal distribution, linearity and homoscedacity were checked. Moreover, according to factor analysis 7 subscales have been revealed within the BSS. Cronbach's alpha was 0.801 for the first subscale, 0.802 for the second, 0.659 for the third, 0.846 for the fourth, 0.706 for the fifth, 0.537 for the sixth, and 0.530 for the seventh.

\section{DIscussion}

Measuring women's satisfaction with their birth experience has been problematic. Every woman's perception of birth is important, which within this study is conceptualised as "birth satisfaction'5,6,8,10. It has been also validated in Scotland (UK) and has shown remarkable stability and comparability, and similarly in Greece e,8,10,12. $^{\text {. }}$

In our study, the Greek-BSS showed high overall internal consistency (Cronbach's alpha value: $0.876, p<0.0001$ ) and good reliability.

\section{Figure 3. ROC curve for Greek BSS}

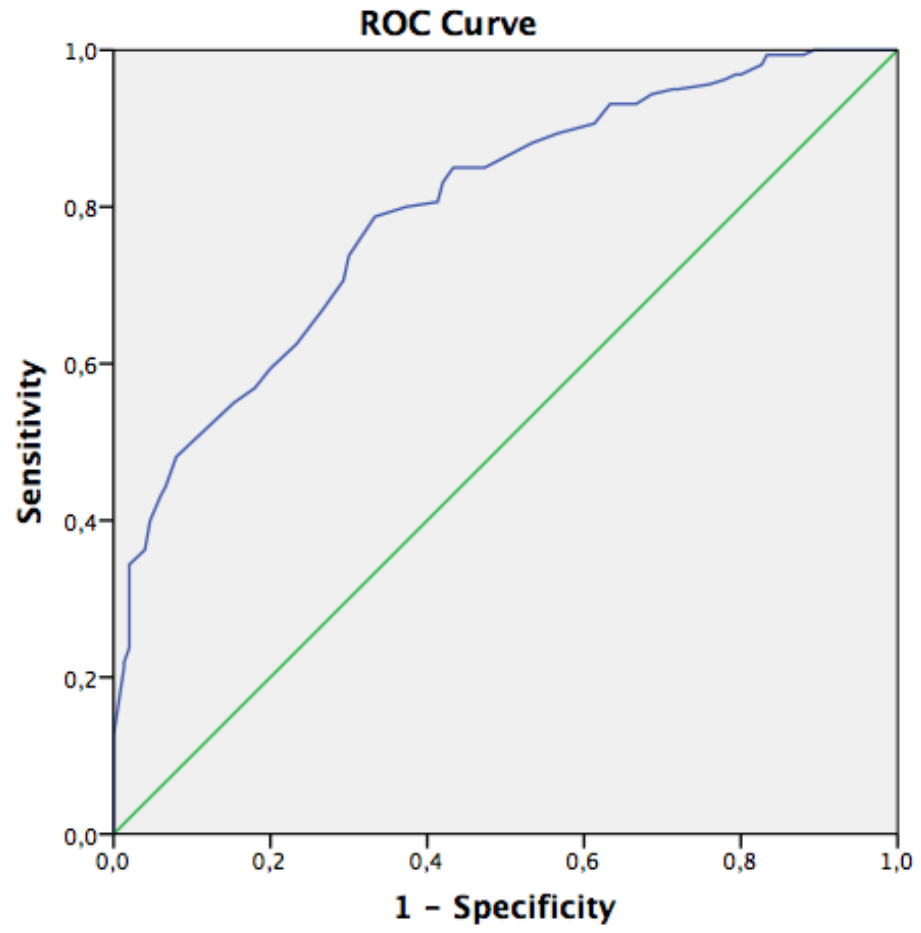

Diagonal segments are produced by ties.

The Exploratory Factor Analysis (EFA) on the 30-item GreekBSS revealed 7 orthogonal factors (KMO measure of sampling adequacy $=0.856$ and Bartlett's test of sphericity $=2999.806, \mathrm{df}=435$, $\mathrm{p}<0.0005)$, whereas in the Scotland validation study a three-factor model comprising correlated factors of quality-of-care provision (4-items), women's personal attributes (2-items), and stress experienced during labour (4-items), resulting in a 10-item scale, was found to offer an adequate fit to the data $\left(x 2\left[\mathrm{df}^{1} / 432\right]=70.47\right.$, $x 2 / d f=2.20, \quad p<0.001, \quad C F \mid \frac{1}{4} 40.93, \quad R M S E A=0.08, \quad R M R=0.05$ and SRMR1/40.07). Our findings confirm the multidimensionality of BSS, demonstrating a seven-factor structure (F1: 'Quality of care', F2: 'Pain and Stress management', F3: 'Feelings and Support during labour', F4: 'Medicalization', F5: 'Birth Experience', F6: 'Healthy Mother and Baby', F7: 'Skin-to-Skin') 5,8,10,12

Moreover, a Bartlett's test of sphericity with $(p<0.05)$ and a KaiserMeyer-Olkin (KMO) measure of sampling adequacy of 0.856 were used in performing this factor analysis. A factor was considered important if its eigenvalue exceeded 114 . As factor analysis found 7 independent subscales, subsequent Cronbach's alphas were separately carried out for each subscale, to highlight how the items group together. According to factor analysis 7 subscales have been revealed within the GreekBSS. Cronbach's alpha was 0.801 for the first subscale, 0.802 for the second, 0.659 for the third, 0.846 for the fourth, 0.706 for the fifth, 0.537 for the sixth, and 0.530 for the seventh.

In the Scotland validation study the original additional 20 items on the BSS did not demonstrate satisfactory levels of statistical validity and so were removed, which trimmed the questionnaire from a 30- to a 10-item questionnaire, with a possible range of scores lying between $\mathrm{O}$ and 40 (O representing least satisfaction and 40 most), using a O-4 scaling per item 5,8,10,12. On the other hand, according to the GreekBSS validation study, 2 of 30 items were excluded from the analysis, 
which were not important for Greek women ${ }^{5,6,8,10}$. These items were: (1) 'I coped well during my birth', and (13) 'I had the same midwife throughout the entire process of labour and delivery ${ }^{5,8,10,12}$. These items were also not included in the Scotland validation study, for different reasons $s^{5,8,10,12}$.

The 10 items of the Scotland validation study are the following: (Q1) 'I came through childbirth virtually unscathed', which is included in the F6 (Healthy Mother and Baby) of the Greek validation study, $5,10,12$, whereas in the Scotland study it is included in the factor 'Stress experienced during labour'5,8,10,12. Having an instrumental intervention or caesarean section is inextricably linked to receiving an obstetric injury ${ }^{17,18,19,20}$ with depressed scores on the Edinburgh Postnatal Depression Scale from some of those in reception of an operative childbirth and higher weighted scores for obstetric procedures ${ }^{21}$. Induced labour is also associated with more pain and ultimately less birth satisfaction 22, 23. (Q2) 'I thought my labour was excessively long', (Q7) 'I found giving birth a distressing experience', and (Q9) 'I was not distressed at all during labour', are included in the same factor in the two studies and this is called 'Pain and Stress Management'. (Q3) 'The delivery-room staff encouraged me to make decisions about how I wanted my birth to progress', (Q5) 'I felt well-supported by staff during my labour and birth', (Q6) 'The staff communicated well with me during labour', and (Q10) 'The delivery room was clean and hygienic', are also included in the same factor of the two studies, and this is called 'Quality of care'. (Q4) 'I felt anxious during my labour and birth' and (Q8) 'I felt out of control during my birth experience', are included in the F7 ('Feelings and Support during labour') of the Greek study, whereas in the Scotland study these are included in the factor 'Women's attributes'5,8,10,12.

According to (Q2), 'I thought my labour was excessively long', lengthy labour is a birth satisfaction indicator, with an associated increase in reports of pain and dissatisfaction with the experience ${ }^{22,23,24}$. Having a long labour is potentially compounded by parity, related obstetric factors, anxiety and reduced personal control ${ }^{20,21,22}$. Concerning (Q3), 'The delivery-room staff encouraged me to make decisions about how I wanted my birth to progress', providing choice profoundly affects women's experiences of labour and birth ${ }^{4,25,26}$; which necessitates that maternity-care professionals empower women with knowledge to become constructive decision-makers 25 in relation to how they would like their labour to be managed ${ }^{21,28,29}$.

Also, in accordance with (Q4), "I felt anxious during my labour and birth', anxious women have a predisposition towards having negative birth expectations ${ }^{30}$, which renders midwives accountable for instilling confidence through delivering effective preparatory education ${ }^{31}$. Preparation for childbirth palpably influences birth satisfaction ${ }^{3}$, with engagers more confident and able to cope ${ }^{31,32}$. It also enhances selfefficacy ${ }^{25}$, which has been shown to reduce pain experience ${ }^{24}$.

The Scotland validation study for (Q5), "I felt well supported by staff during my labour and birth'29, meta-analysed 14 trials ( $n=5020$ women) that measured the effects of continuous support from caregivers during labour on childbearing women's labour experience. Continuous support was associated with reduced requests for pain relief. Numbers receiving operative vaginal childbirth and caesarean section were also reduced $^{31}$. In general, women who felt supported viewed their birth experience more favourably (6 trials) ${ }^{29}$.

In relation to (Q6), 'The staff communicated well with me during labour', quality of care provision is multifaceted. Aspects of relationships with staff are important ${ }^{20}$; quality relationships include being offered information from which to make choices in plain language, and staff being honest and consistent about what is provided ${ }^{31,33}$. Staff also require to be flexible, informal, interested and friendly ${ }^{31,33}$, and at the same time being professional, skilled and knowledgeable ${ }^{31,33}$. In the presence of negative birth perceptions and perceived low-quality relationships with care providers, women's long-term memories of negative experiences can be preserved ${ }^{31,33,35}$. When women feel treated as objects, such disaffirming is significantly correlated with negative birth perceptions ${ }^{20,31,33}$. Negative outcomes are related to disaffirmation expressed through verbal and nonverbal provider interactions, with healing effects reported from supportive interactions ${ }^{31,33}$.

According to (Q7), 'I found giving birth a distressing experience', distress experienced during labour affects birth experience ${ }^{35}$, with this inextricably linked to receiving an obstetric injury ${ }^{20,31,33,36}$, such as caesarean section $31,33,36$.

In the Scotland validation study, in accordance with (Q8), "I felt out of control during my birth experience', feeling in control has been securely linked with women's experiences of birth satisfaction ${ }^{37,38}$. Concerning (Q9), 'I was not distressed at all during labour', the amount and type of pain experienced during labour is a birth satisfaction indicator39, with primigravidas experiencing greater pain than multiparous women ${ }^{31,33,40}$.

Finally, for (Q10), 'The delivery room was clean and hygienic', the environment is associated with making birth a more satisfying experience $^{33}$. For most women, cleanliness is an essential feature, with uncontaminated delivery rooms considered safe places where infection risks are minimized ${ }^{33}$.

Finally, to the best of our knowledge, this is the first study to compare satisfied and not-satisfied mothers; in analysing the scale sensitivity in the detection of satisfied women at the 37 cut-off score, the sensitivity was $73,8 \%$ and specificity $70 \%$. In particular, this study analyses the cut-off score, which validates the interpretation of the results and the associated discussion. Until now the BSS was scored so that higher scores indicate better birth satisfaction, however the authors propose the instrument to be scored in the different direction, as in other screening tools, like EPDS.

As a result, we have scored the status satisfied as $O$ (non-disease) and the status not- satisfied (disease) as 1, for the criterion-validity statistical analysis. Future studies with the BSS might also usefully examine alternative measures to assess validity, beyond the factors that were used in the current study, like disappointment with delivery ${ }^{41}$ and the results of the 10-item BSS-R, which will be embedded in the BSS scale, particularly as this measure has recently been recommended by $\mathrm{ICHOM}$ for global $\mathrm{use}^{42}$. This study is a potentially important contribution to the area of birth satisfaction employing this increasingly used Scale.

\section{CONGLUSIONS}

The Greek-BSS has shown to be a robust tool for midwives, obstetricians and maternity care managers to measure postnatal women's birth satisfaction. According to the ROC analysis, with the scale sensitivity in the detection of satisfied women at the 37 cutoff score, the sensitivity was $73,8 \%$ and the specificity was $70 \%$. In terms of impact, the BSS can be requested for use by researchers to collect data both nationally and internationally, with results potentially correlated with other measures (e.g. pain and/or depression scales).

\section{REFERENGES}

1. Ware J. 1994. Monitoring health care from the patient's point of view, Hospital Practice 15, 12-17.

doi: 10.1080/21548331.1994.11443012 


\section{Research paper}

2. Mahon, P.Y. 1996. An analysis of the concept 'patient satisfaction' as it relates to contemporary nursing care, Journal of Advanced Nursing, Vol. 24, pp. 1241-8. doi: 10.1111/j.1365-2648.1996.tb01031.x

3. Dannenbring, D., Stevens, M.J. and House, A.E. 1997. Predictors of childbirth pain and maternal satisfaction, Journal of Behavioural Medicine, Vol. 20 No. 2, pp. 127-42. doi: 10.1023/a:1025526610524

4. Gibbens, J., Thomson, A. 2001. Women's expectations and experiences of childbirth. Midwifery. Vol. 17, pp. 302-13. doi: 10.1054/midw.2001.0263

5. Lomas J, Dore S, Enkin M, Mitchell A: The labor and delivery satisfaction index-the development and evaluation of a soft outcome measure. Birth1987,14:125-129. doi: 10.1111/j.1523-536x.1987.tb01472.x

6. Sawyer et al. (2013) Measures of satisfaction with care during labour and birth: a comparative review. BMC Pregnancy and Childbirth 2013: $13: 108$. doi: 10.1186/1471-2393-13-108

7. Hollins Martin, C., Fleming V. 2009. The birth satisfaction scale. International Journal of Health Care. 24:124-135. doi: 10.1108/09526861111105086

8. Hollins Martin, C., Martin, C.R. 2014. Development and psychometric properties of the Birth Satisfaction Scale-Revised (BSS-R). Midwifery. 30: 610-619. doi: 10.1016/j.midw.2013.10.006

9. Barbosa-Leiker C., Hollins Martin CJ., Martin CR. (2015) Psychometric properties of the Birth Satisfaction Scale-Revised (BSS-R) for US mothers. Journal of Reproductive and Infant Psychology. 33(5):504-511. doi: 10.1080/02646838.2015.1024211

10. Vardavaki Z., Hollins Martin CJ., Martin C. (2015). Construct and content validity of the Greek version of the Birth Satisfaction Scale (G-BSS). Journal of Reproductive and Infant Psychology. 33(5), 488-503. doi: 10.1080/02646838.2015.1035235

11. Bowling A. 2002. Research Methods in Health: Investigating health and health services, 2nd edn, Maidenhead England: Open University Press. doi: 10.7748/nr.10.2.81.s11

12. Hollins Martin, C., Snowden, A., Martin, C.R. 2012. Concurrent analysis: validation of the domains within the Birth Satisfaction Scale. Journal of Reproductive and Infant Psychology. 1-14. doi: 10.1080/02646838.2012.710833

13. Tabachnick B., Fidell L. 2007. Using multivariate statistics. 3rd ed. N.Y.: Addison- Wesley- Longman.

14. Kaiser, HF., 1960. The application of electronic computers to factor analysis. Educational and Psychological Measurement, (20) 141151. doi: 10.1177/001316446002000116

15. Hakstian A. R., Rogers W.D. \& Cattell R.B. 1982. The behaviour of numbers factors rules with simulated data. Multivariate Behavioral Research 17, 193-219. doi: 10.1207/s15327906mbr1702_3

16. Morrison, D.F. 1976. Multivariate statistical methods (2nd edition) New York, McGraw-Hill. doi: 10.1002/bimj.19700120121

17. Geissbuehler V., Eberhard, J. 2002. Fear of childbirth during pregnancy: a study of more than 8000 pregnant women. J. Psychosom. Obstet. Gynecol. 23, 229-235. doi: 10.3109/01674820209074677

18. McKenzie-McHarg K., 2004. Traumatic birth: understanding predictors, triggers, and counseling process is essential to treatment. Birth 31, 219-221. doi: 10.1111/j.0730-7659.2004.00308.x

19. Beck, C.T. 2009. Birth trauma and its sequelae. J. Trauma Dissociation 10, 189-203. doi: 10.1080/15299730802624528

20. Sorenson D.S., Tschetter, L. 2010. Prevalence of negative birth perception, disaffirmation, perinatal trauma symptoms, and depression among postpartum women. Perspect. Psychiatr. Care 46, 14-25. doi: 10.1111/j.1744-6163.2009.00234.x

21. Brown S., Lumley, J. 1994. Satisfaction with care in labour and birth: a survey of 790 Australian women. Birth 21, 4-13. doi: 10.1111/j.1523-536x.1994.tb00909.x

22. Niven C., Gijsbers K. 1984. A study of labor pain using the McGill pain questionnaire. Soc. Sci. Med. 19, 1347-1351. doi: 10.1016/0277-9536(84)90023-6

23. Faure, E.A.M. 1991. The pain of parturition. Semin. Perinatol. 15, 342-347.

24. Scott-Palmer J., Skevington, S.M. 1981. Pain during childbirth and locus of control. J. Psychosom. Res. 25, 151-155. doi: 10.1016/0022-3999(81)90027-1

25. Handfield, B., Bell, R. 1995. Do childbirth preparation classes influence decision making about labour and postpartum issues? Birth 22, 153-160. doi: 10.1111/j.1523-536x.1995.tb00692.x

26. Hall, S.M., Holloway, I.M. 1998. Staying in control: women's experiences of labour in water. Midwifery 14, 30-36. doi: 10.1016/s0266-6138(98)90112-7

27. Melender H.L., 2002. Fears and coping strategies associated with pregnancy and childbirth in Finland. J. Midwifery Womens Health 47, 256-263. doi: 10.1016/s1526-9523(02)00263-5

28. Halldorsdottir S., Karlsdottir, S.I. 1996. Journeying through labour and delivery: perceptions of women who have given birth. Midwifery 12, 48-61. doi: 10.1016/s0266-6138(96)90002-9

29. Hodnett, E.D. 1996. Nursing support of the labouring woman. J. Obstet. Gynecol. Neonatal Nurs. 25, 257-264. doi: 10.1111/j.1552-6909.1996.tb02434.x

30. Heaman M., Beaton, J.Gupton, A. 1992. A comparison of childbirth expectations in high risk and low risk pregnant women. Clin. Nurs. Res. 1, 252-265. doi: 10.1177/105477389200100305

31. Wong N, Browne J, Ferguson S, Taylor J, Davis D (2015) Getting the first birth right: A retrospective study of outcomes for lowrisk primiparous women receiving standard care versus midwifery model of care in the same tertiary hospital . Women and Birth 28 (2015) 279-284. doi: 10.1016/j.wombi.2015.06.005

32. Sinclair M. 1999. The childbirth self-efficacy inventory: a replication study. J. Adv. Nurs. 30, 1416-1423. doi: 10.1046/j.1365-2648.1999.01230.x

33. Proctor S. 1998. What determines quality in maternity care? 


\section{Research paper}

Comparing the perceptions of childbearing women and midwives. Birth 25, 85-93. doi: 10.1046/j.1523-536x.1998.00085.x

34. Stadlmayr W., Amsler F., Lemola S., et al. 2006. Memory of childbirth in the second year: the long term effect of a negative birth experience and its modulation by the perceived intranatal relationship with caregivers. J. Psychosom. Obstet. Gynecol. 27, 211-224.

doi: 10.1080/01674820600804276

35. Alehagen, S., Wijma, B. 2000. Can women's cognitive appraisal be registered throughout childbirth? Gynecol. Obstet. Invest. 49, 31-35. doi: 10.1159/000010209

36. Wax J., Cartin, A., Pinette, M., Blackstone, J. 2004. Patient choice caesarean: an evidence based view. Obstet. Gynecol. Surv. 59, 601-616. doi: 10.1097/01.ogx.0000133942.76239.57

37. Green, J.M., Baston, H.A., Easton, S.C, McCormick, F. 2003. Greater Expectations: The Inter-Relationship between Women's Expectations and Experience of Decision-Making, Continuity, Choice and Control in Labor, and Psychological Outcomes, Summary Report. Mother and Infant Research Unit (University of Leeds), Leeds.

38. Goodman, P., Mackay, M.C., Tavakoli, A.S., 2004. Factors related to childbirth satisfaction. J. Adv. Nurs. 46, 212-219. doi: 10.1111/j.1365-2648.2003.02981.x

39. Quine L., Rutter, D.R., Gowan, S. 1993. Women's satisfactionwith the quality of the birth experience: a prospective study of social and psychological predictors. J. Reprod. Infant Psychol. 11, 107-113. doi: 10.1080/02646839308403202

40. Melzack R., Taenzer, P., Feldman, P., Kinch, R. 1984. Labor is still painful after prepared childbirth. Can. Med. J. 125, 357-363. doi: 10.1016/0304-3959(81)90537-6

41. Saisto et al (2001) Psychosocial predictors of disappointment with delivery and puerperal depression. A longitudinal study. Acta Obstet Gynecol Scand 2001; 80: 39-45

doi: 10.1080/791201832

42. ICHOM (2017) Pregnancy and Childbirth data Collection Reference Guide. Version 1.0.3 Revised: April 10th, 2017 